\title{
Beyond Virtual Replicas: 3D Modeling and Maltese Prehistoric Architecture
}

\author{
Filippo Stanco ${ }^{1}$ and Davide Tanasi ${ }^{2}$ \\ ${ }^{1}$ Department of Mathematics and Computer Science, University of Catania, Viale A. Doria 6, 95125 Catania, Italy \\ ${ }^{2}$ The College of Global Studies, AUMCAS, Arcadia University, Via Roma 124, 96100 Siracusa, Italy
}

Correspondence should be addressed to Davide Tanasi; tanasid@arcadia.edu

Received 5 December 2012; Revised 23 May 2013; Accepted 24 June 2013

Academic Editor: Constantin Papaodysseus

Copyright (C) 2013 F. Stanco and D. Tanasi. This is an open access article distributed under the Creative Commons Attribution License, which permits unrestricted use, distribution, and reproduction in any medium, provided the original work is properly cited.

\begin{abstract}
In the past decade, computer graphics have become strategic for the development of projects aimed at the interpretation of archaeological evidence and the dissemination of scientific results to the public. Among all the solutions available, the use of 3D models is particularly relevant for the reconstruction of poorly preserved sites and monuments destroyed by natural causes or human actions. These digital replicas are, at the same time, a virtual environment that can be used as a tool for the interpretative hypotheses of archaeologists and as an effective medium for a visual description of the cultural heritage. In this paper, the innovative methodology and aims and outcomes of a virtual reconstruction of the Borg in-Nadur megalithic temple, carried out by Archeomatica Project of the University of Catania, are offered as a case study for a virtual archaeology of prehistoric Malta.
\end{abstract}

\section{Virtual Archaeology: The Future of the Past}

In the last fifty years, the growing use of computer applications has become a main feature in cultural heritage preservation policies [1,2]. Since the 1990s when computer science was oriented towards the creation of tools and solutions for the archive and management of quantitative data, to the current development of virtual models and the dissemination of knowledge, computer applications came to embrace a true theoretical approach for the problems of archaeology. Indeed, digital tools are now able to direct interpretative models and affect the language and contents of the study of the past. Nowadays, among all the branches of computer science, computer graphics are the more effective tool for dealing with cultural contents [3]. Their importance lie in the four main steps of the archaeological process: fieldwork, recording, interpreting, and dissemination of results. Although during an excavation the technological applications are mainly restricted to the use of laser scanners and 3D GIS, where archaeologists can be considered as mere "users", in the moment of decoding ancient data and in the subsequent phase of encoding and simplifying them, research strategies and goals of archaeology and computer science may converge [4]. In this perspective, the digital solution appears today as the most successful strategy for passing on our shared heritage to future generations.

Heritage is considered to encompass more than the archaeological retrieval of past material evidence. It also includes tradition, artistic expression, and cultural evidence. UNESCO defines heritage as "our legacy from the past, what we live with today, and what we pass on to future generations" (http://whc.unesco.org/). In both definitions, the concept is not restricted to human-made artefacts but includes natural landscape sites and abstract cultural manifestations.

The term virtual heritage is similar to that of "virtual archaeology" intended as "digital reconstructive archaeology applied to the reconstruction of three-dimensional archaeological ecosystems." But independently of the term's meaning the common ground for research seems to be to approach virtual archaeology (henceforth, VA) as a means of producing tools that aid understanding. The birth of VA was not simply caused by the proliferation of $3 \mathrm{D}$ modeling techniques in many fields of knowledge, but as a necessity to archive an overgrowing amount of data and to create the best medium 
to communicate those data with a visual language. From this point of view, the application of $3 \mathrm{D}$ reconstructions, obtained using different techniques, became the core area of study in VA, particularly for its potential of facilitating the sort of cognitive interaction offered by a 3D model [3]. In this way, virtuality turns into a communication method more effectively if applied to particular fields, especially archaeological sites which are well preserved but are not accessible or sites which are not preserved but known through traditional documentation [5].

The process of creating images for the visualisation of historical buildings is not exclusive to the digital age. Recent computer-generated imagery represents a modern version of previous hand-drawn reconstructions, and likewise old image production techniques aim at producing visual outputs from the acquired or generated three-dimensional information. Heritage virtual models disseminated through the Internet and numerous websites provide a vast number of examples with diverse objectives and presentation technologies.

Directly linked to technological resources, virtual heritage has benefited from the recent fast growing stream of digital advancements originating from academic, government, and industry laboratories [6]. Historically, virtual reconstruction projects basically targeted three separate groups: the conservator, who expected to encounter relevant documentation, the historian who sought interpretation, and the general public, which required visual realism [6]. Each user category holds its set of demands, expecting diverse and specific results that determine the degree of success of a reconstruction project. Equally, virtual heritage contributes in different ways to each group.

The historical reliability of the 3D models produced by the growing number of virtual reconstructions constitutes a major concern expressed by several researchers worldwide. The necessity to recognise whether an image portrays a scientifically based version of a historical building or artefact comprises a fundamental question affecting all virtual heritage projects.

Furthermore, one largely neglected potential of "virtuality" centered on evidence coming from the past is that it can offer a valuable experimental environment in which to test the reliability of one's assumptions. From this point of view, $3 \mathrm{D}$ computer graphics came to be considered on the same level as archaeology itself, as a digital version of archaeology by experiment [7], characterised by the study of the "practice supporting the theory". It aims to replicate experiments involving site formation process and test methodological assumptions by applying them to known contexts. In the same way similar research can be conducted virtually, interacting with a $3 \mathrm{D}$ model replicating reality [8]. In this sense of a cognitive tool, the use of 3D models in archaeological research can be intended as a sort of benchmark of what the perceptual senses and the mind perceived in the first instance: a sort of "seeing causes believing" opposed to a simple and sometimes misleading "seeing is believing" which is often altered by the cultural biases of the archaeologists [9]. So digital technology is not only used to provide tools of discovery and communication but mostly interactive feedbacks.
In this scenario is situated the multidisciplinary project of computer science solutions for Cultural Heritage preservation "Archeomatica Project" (http://www.archeomatica.unict .it/), that produced the application presented in this paper.

\section{From Field to Screen: Archaeological 3D Modeling}

Against this background, in 2007 an interdisciplinary research programme of VA, named Archeomatica Project, was begun by the Image Processing Laboratory of the University of Catania (http://www.archeomatica.unict.it/). It is aimed to create new tools for archaeological research within the field of $2 \mathrm{D}$ digital imaging and $3 \mathrm{D}$ graphics, in particular to (1) produce automatic systems of recognition and classification of graphic data; (2) to develop virtual models of archaeological sites and items with a high degree of accuracy following the data obtained during excavation and study, through the use of laser scanner and 3D modeling techniques $[3,10-$ 12].

The essence of this project is a cognitive process based on a peer-to-peer exchange of knowledge between experts of computer science and archaeology working side by side. The Archeomatica Project, which represents through its scientific results one of the most recent trends in VA and in the modern policies in the conservation of archaeological heritage, is also aimed at defining a common multidisciplinary language to improve the quality of the message of this new discipline to the outside world [12].

Several achievements were obtained by the Archeomatica Project through archaeological 3D modeling, namely, the recreation of landscapes, architecture, and objects by digital means based upon the current state of the salvaged monuments integrated with the data coming from historical and archaeological research using software for developing 3D models [13]. 3D modeling is probably the most popular computer-based technique applied to cultural heritage as it represents the core of the "serious games" used in many multimedia projects [14]. The archaeological 3D modeling is not just a simple cognitive tool used to reproduce virtual aspects of the past, like objects of everyday life, but to improve knowledge and aid or facilitate comprehension. It is also, above all, a method of recording all the archaeological data in a much more complete way than traditional photography and drawing; besides, it is also a tool aiding interpretation for researchers involved in the theoretical reconstruction of the past itself. From this point of view, it is a kind of virtual benchmark of the archaeologists' theories where the hypothesis is tested and corrected in order to produce a truthful image of something buried by time, a kind of "solid modeling to illustrate the monument" becoming "solid modeling to analyse the monument" [15].

A useful field for the application of this technique is prehistory, for which the scarcity of iconographic sources and the generally poor state of conservation of the finds make both processes of decoding the information and of transmitting knowledge to the public extremely complex [16]. And it is also extremely suitable for the virtual reconstruction of vanished heritage due to the growing capacities of digital 
media to replicate and interpret lost or inaccessible cultural heritage sites.

\section{Computer Graphics and Maltese Prehistory}

The research carried out between 1987 and 1994 by the AngloMaltese team working at the Brochtorff Circle at Xaghra (Gozo, [17]) resulted in seminal contributions for the virtual reconstruction of some features of Maltese prehistoric sites. These include the study of intervisibility and of the influence of light sources on ritual practices, the interaction between the participating audience and the space defined by the architecture of the temples, alternative virtual reconstructions of ritual furniture and liturgical artefacts, and reconstruction of no longer existing structures represented in later graphic and photographic documentation; these are just a few examples of those achievements [18].

Of particular importance is the work of Chalmers and Debattista [19] in which for the first time guidelines for the virtual reconstruction in 3D modeling of Maltese megalithic architecture (both built and rock-cut) are provided. Relevant was also the effort to apply methodologies from computer games, like narrative and environment interactivity, for enhancing the onsite evaluation of visible and invisible features of Mnjadra temple, carried out by an Australian researcher [20].

In 2005, the Maltese Ministry for Resources and Rural Affairs carried out an update of available documentation of Ggantija, Hagar Qim and Mnajdra temples applying combined techniques as topographic surveys, photogrammetry and laser scanning [21].

In 2006 some major projects were carried out by Heritage Malta as part of its long-term objective of creating a visual portfolio of all its sites as tools for better heritage management and monitoring [22]. Among its major achievements is the completion of the 3D models of the temple sites of Hagar Qim and Mnajdra, which formed part of the groundwork for a much larger project which aimed to build shelters to protect the temples from natural and human induced causes of deterioration. At the same time, Heritage Malta commenced preparations for the $3 \mathrm{D}$ modeling, using laser scanning technology of three other sites, namely, Ta' Hagrat, Skorba, and the interior of the Hypogeum. In a project promoted and implemented jointly by the Department of Archaeology of the University of Cambridge (UK) and the National Museum of Archaeology (Heritage Malta), funded by the Templeton Foundation, emphasis was placed on the digitisation of archaeological artefacts and sites related to Maltese prehistoric figurative art.

\section{The Virtual Model of the Borg in-Nadur Temple}

In the summer of 2010, an interdisciplinary team from the Archeomatica Project was actively involved in a research plan drawn up by Arcadia University of Philadelphia to understand the temple of Borg in-Nadur in Malta, in collaboration with the University of Malta and Heritage Malta (the Maltese national agency responsible for the management of museums and archaeological sites). The temple in question goes back to the end of the fourth millennium $\mathrm{BC}$ but was reoccupied and reused from the beginning of the third millennium right down to the Phoenician settlement of the island in the course of the eighth century BC.

About 20 megalithic sites are known in Malta and Gozo and together they probably represent the most relevant tourist attraction of the archipelago and, indirectly, the backbone of its economy. However, the temple of Borg in-Nadur is less well known than the rest, even though it started off as a major attraction for grand tourists and travellers in the Early Modern and Colonial periods. It was explored in the second half of the 1920s by a team of British archaeologists. The excavations uncovered a monumental sacred complex, characterised by a singular plan including a megalithic enclosure with different cult places. A large number of finds were unearthed, demonstrating the wealth of the community using the site. At that time, the conditions of the temple building were rather good. Orthostats and megaliths were still standing; paving slabs and cultic stone objects located on them were preserved in situ, and a good part of the original plan of the sanctuary area could be clearly made out. The preliminary reports of the explorations, published promptly in 1923, 1925, and 1929 , were accompanied by a thorough drawn and photographic documentation including an accurate measurements of nearly all megaliths (Figure 1).

In the past 80 years, for different reasons this site was forgotten and generally neglected with the result that the current conditions of the entire archaeological area are unfortunately rather poor (Figure 2). As a consequence, Borg in-Nadur has not been included in any tourist itinerary, and the site is currently only open to the public by appointment. For these reasons, the attempt to develop a virtual archaeology project around the site seems timely especially to clarify some features of the temple which now appear to be lost and to offer a new tool for promoting the site. In this context, the work done to date in the field of computer graphics and digital imaging on Maltese prehistoric sites provided useful information for planning the Borg in-Nadur reconstruction.

In the case of the megalithic temple, the starting point for this archaeological 3D model work (Figure 3) was the collection of all the graphic and photographic documentation available for this monument, consisting mostly of publications from the 1920s and carrying out a site survey to evaluate what has been lost or discovered. In addition, extruded multilayered plans containing information about orography and high resolution aerial pictures of the Marsaxlokk Bay area, provided by the Malta Environment and Planning Authority (http://www.mepa.org.mt/), were elaborated in order to develop a digital elevation model (DEM, [23]). The superimposition of the pictures over the DEM has not been aimed to recreate the original landscape but just for suggesting the "visualscape" of the temple, as theorised by Llobera [24]. The temple has been rebuilt using the measurements provided in Murray's reports, while all the other structures were reconstructed using dimensions recorded on site or through comparisons with other temple sites. The juxtaposition of the model of the temple in the DEM was achieved with an acceptable range of error thanks to the 


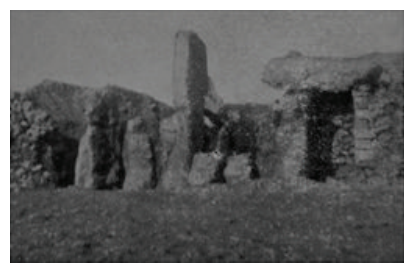

(a)

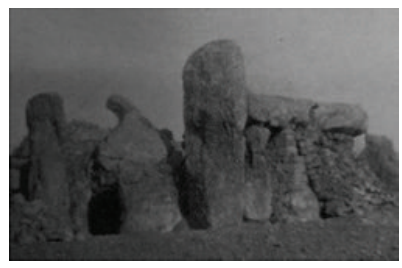

(b)

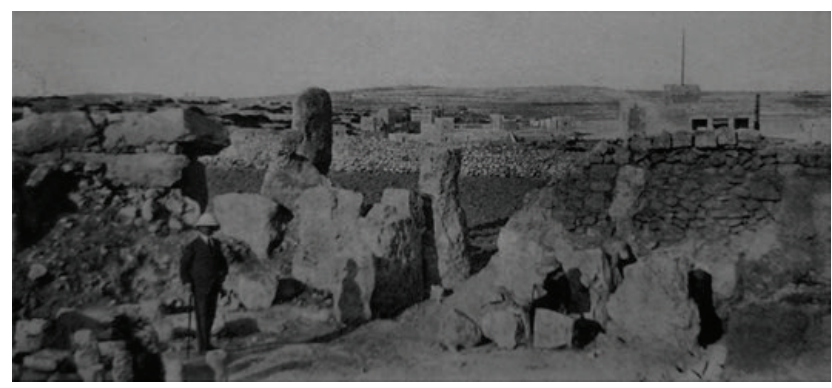

(c)

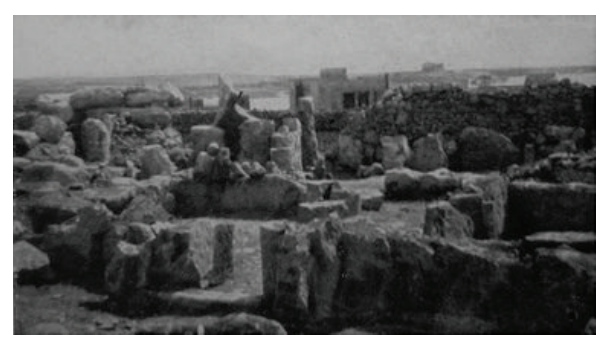

(d)

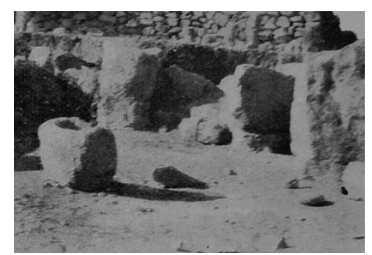

(f)

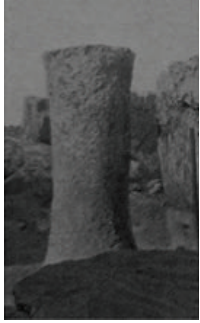

(e)

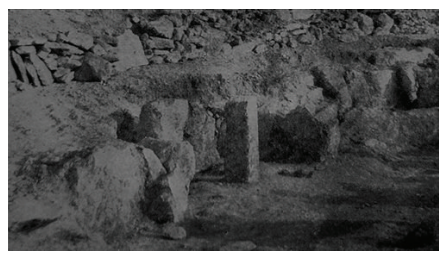

(g)
FIGURE 1: The temple at the time of Murray's excavations: (a) general view from the north-east (1923); (b) great Upright from the southeast (1923); (c) great entrance, showing megalith built into wall (1925); (d) north-west Apse (1925); (e) large biconical pillar (1923); (f) mortar in situ (1925); (g) niche showing the three standing stones (1923).

presence of official trig pillars in the surroundings of the temple.

The reconstruction work has been completely carried out using the Blender 3D suite (http://www.blender.org/), an open source cross-platform software for modeling, rendering, animation, postproduction, creation, and playback of interactive $3 \mathrm{D}$ contents. The blender is extremely versatile, functional, and constantly open to implementations based on the research of its application in various fields, including archaeology [12].

The 3D model was not intended to reconstruct in elevation the missing parts of the temple but was aimed at rediscovering digitally what was found by the archaeologists nearly 80 years ago. Therefore, the model of the temple

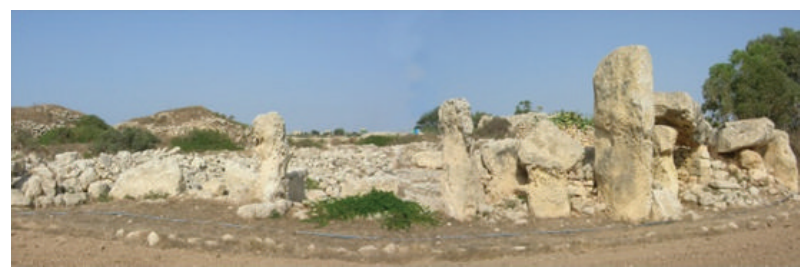

(a)

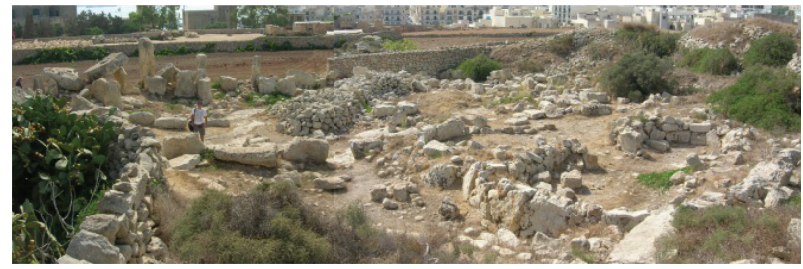

(b)

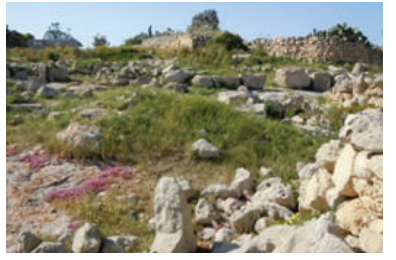

(c)

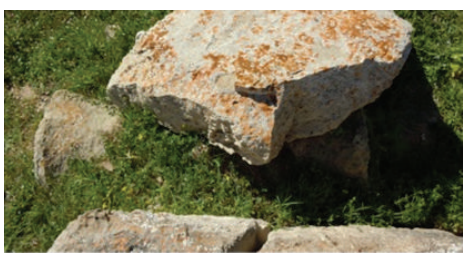

(e)

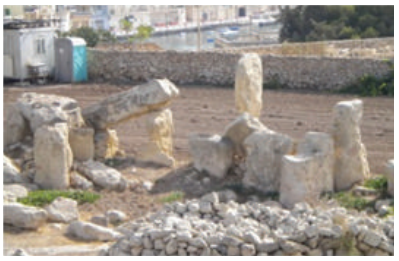

(d)

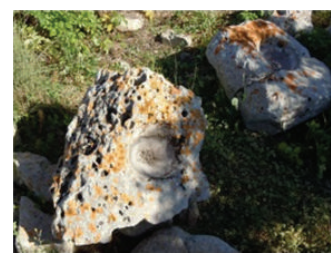

(f)
FIGURE 2: Current conditions of the temple: (a) main entrance to the Forecourt, from the east; (b) overview of the Forecourt and the Apsidal Building, from the west; (c) southern Forecourt and Apsidal Building, from the north; (d) dolmen and Great Upright from west; (e) large biconical pillar, now half buried; (f) grinders grouped together in the southern Forecourt.

and of the surrounding territory became a useful virtual environment for carrying out tests of intervisibility between the temple and another two adjacent sites occupied in the same period, namely, the Borg in-Nadur village and the Ghar Dalam cave. Furthermore, the visibility of the temple's ruins from the sea and from the Roman Villa of Ta' Kaccatura was checked in order to validate the visual importance of the site in later times. In order to add realism to the digital replica, a study of light sources was carried out, simulating a complete cycle of the sun on mid-summer day through the use of the Radiance raytracer (http://radsite.lbl.gov/radiance/). The final outcome of the processing and postprocessing phases is a 10-minute video (http://www.archeomatica.unict.it/ in the section "3D Modeling-Malta"), in which the virtually rebuilt megalithic temple of Borg in-Nadur is shown in its landscape accompanied by music composed for the project by the Maltese musician Renzo Spiteri (http://www.renzospiteri.com/). 


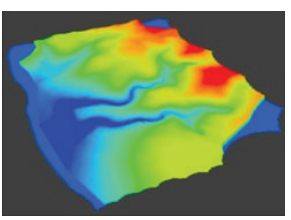

(a)

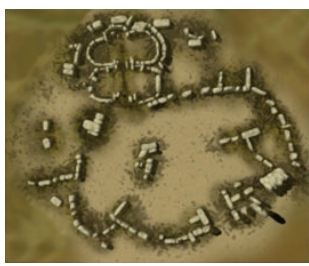

(c)

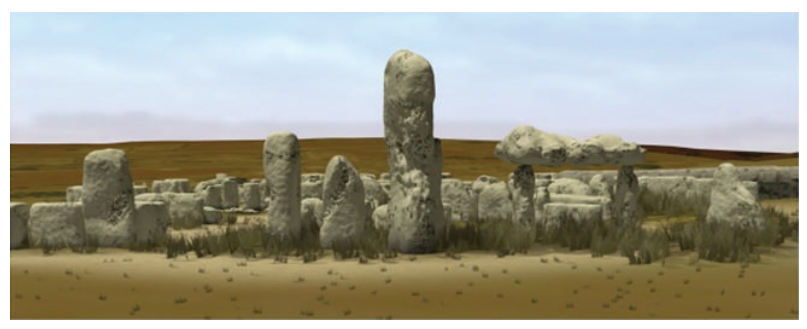

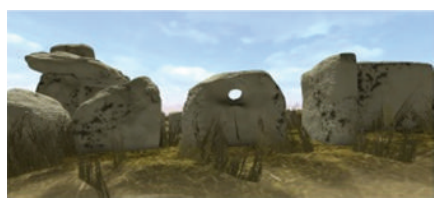

(f) (e)

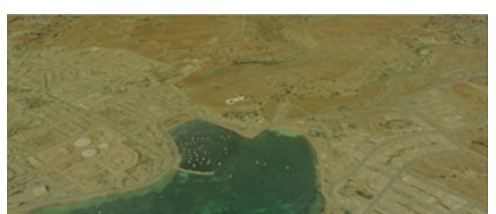

(b)

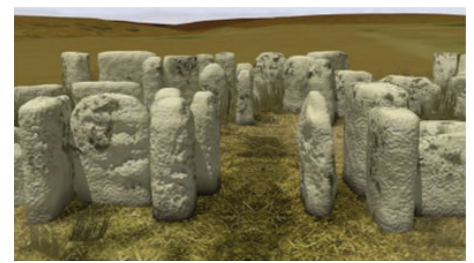

(d)

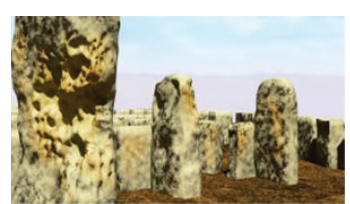

(g)
Figure 3: (a) Digital elevation model (DEM); (b) DEM with a superimposed aerial photograph; (c) 3D model of the temple, aerial view; (d) entrance to Apsidal Building; (e) main entrance to the Forecourt; (f) detail of the pierced megalith on the northern outer wall of the Forecourt; (g) detail of the texture used to represent the limestone.

The last phase of the exercise includes also the development of an interactive 3D model of the temple in the conditions in which it was in the 1920s. An advantage of interactive visualisation is to insert users in the loop. Conversely to passive media such as computer animation, it is now the users that drive the navigation and the inspection of the digital artefact. An interactive system allows users to follow their specific interest while choosing the exploration path, focusing on the details that hit personal interest and giving the possibility to choose the duration of the visualisation session on the basis of the specific insight experience and needs [25].

For making lighter the rendering process without losing quality and limiting interactivity, a system with 17 static stations of observations was developed for the interactive 3D model (Figure 4). In Blender environment, 17 stations with wide-angle cameras, located in specific positions inside the temple area, pointing front, left, right, up, back, and down rendered the scene into 102 views. These views were then smoothly stitched into required fish-eye projections by

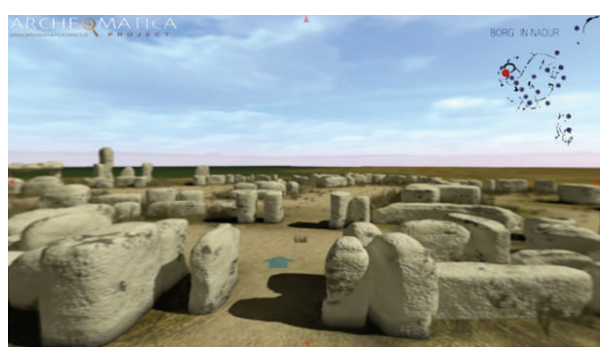

(a)

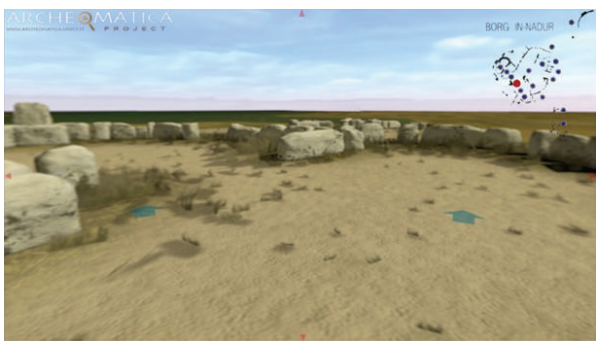

(b)

FIGURE 4: (a-b) Interface of the interactive virtual model (in the upper right corner the interactive map; blue arrows working as link for the navigation stations).

the panorama stitcher Hugin (http://hugin.sourceforge.net/). From the projections, proper textures were extracted for creating 17 spheres, one for each station, inside which the camera of the Blender Game Engine was located. The passage from one station/sphere to another is through simple jumping links. The user can move from one station/sphere to another by clicking on the blue arrows or the red spots on the map. The navigation is not restricted to adjacent areas for not limiting the freedom of users in the interaction, as it could have happened with a predefined path to be followed. The interactive 3D model has been produced using the Blender Game Engine.

The navigation interface includes an interactive map of the temple, located in the upper right corner, indicating the current position of the human-sized avatar moving inside the ruins. It is possible to click on the map every time the users want to change position, as in the popular product of the Virtual Museum of the Ancient via Flaminia project (http://www.vhlab.itabc.cnr.it/flaminia/).

The interactive 3D model of the Borg in-Nadur temple can be download at http://www.archeomatica.unict.it/ in the section "3D Modeling-Malta”.

\section{Conclusions}

In conclusion, the life history of the Borg in-Nadur temple demonstrates that the archaeological heritage is under constant threat and danger: danger to be vandalised or even worse forgotten. Architectural structures and cultural and natural sites are exposed to pollution, tourists, and wars, as well as environmental disasters such as earthquakes, floods, or climatic changes. Hidden aspects of our cultural heritage are also affected by agriculture, changes in agricultural 
regimes due to economic progress, mining, gravel extraction, construction of infrastructure, and the expansion of industrial areas. 3D modeling could be extremely useful for the identification, monitoring, conservation, restoration, and promotion of archaeological sites. 3D computer graphics can support archaeology and the politics of cultural heritage by offering scholars a "sixth sense" for understanding remains from the past, as it allow us to experience it [26]. 3D documentation of still extant archaeological remains or building elements is an important part of collecting the necessary sources for a virtual archaeology project. New developments permit this documentation phase to be accomplished, using tools available for free to obtain correct measurements and ground plans from photographic representations. This is important when preserving archaeological remains, when older phases are reconstructed in a virtual way. The original state, the restored state, and eventual in-between states can be recorded easily through photo modeling techniques [27]. Furthermore, the recent application of 3D computer graphics has proved crucial in planning strategies of conservation and restoration issues concerning monuments that are part of world cultural heritage.

\section{Conflict of Interests}

The authors have no financial obligations or conflict of interests to declare.

\section{Acknowledgments}

The authors are thankful to Emanuele Sangregorio and Simone Tomasello for the development of the interactive 3D model and to Giovanni Gallo and Nicholas Vella for their suggestions that aimed to improve the work. This work was supported by Regione Sicilia PO/FESR 4.1.1.2 under the EMOCUBE Project.

\section{References}

[1] L. MacDonald, Digital Heritage: Applying Digital Imaging to Cultural Heritage Preservation, Butterworth-Heinemann, Oxford, UK, 2006.

[2] E. B. W. Zubrow, "Digital archaeology. A historical context," in Digital Archaeology. Bridging Method and Theory, T. L. Evans and P. Daly, Eds., pp. 3-9, Routledge, London, UK, 2006.

[3] F. Stanco and D. Tanasi, "Experiencing the past: computer graphics in archaeology," in Digital Imaging for Cultural Heritage, S. Battiato, G. Gallo, and F. Stanco, Eds., pp. 1-37, CRC Press, New York, NY, USA, 2011.

[4] P. Daly and T. L. Evans, "Archaeological theory and digital pasts," in Digital Archaeology. Bridging Method and Theory, T. L. Evans and P. Daly, Eds., Routledge, London, UK, 2006.

[5] F. Stanco, D. Tanasi, G. Gallo, M. Buffa, and B. Basile, "Augmented perception of the past. The case of hellenistic Syracuse," Journal of Multimedia, vol. 7, no. 2, pp. 211-216, 2012.

[6] A. C. Addison, "Emerging trends in virtual heritage," IEEE Multimedia, vol. 7, no. 2, pp. 22-25, 2000.

[7] G. Thomas, Experimental Archaeology, Routledge, London, UK, 2009.
[8] M. Moser, S. Hye, G. Goldenberg, K. Hanke, and K. Kovacs, "Digital documentation and visualization of archaeological excavations and finds using 3D scanning technology," in Arqueologica 2.0, Proceedings of 1st International Meeting on Graphic Archaeology and Informatics, Cultural Heritage and Innovation, (Seville June 2009), pp. 351-355, SEAV, Seville, Spain, 2009.

[9] D. C. Dennett, "Seeing is believing," in Perception. Vancouver Studies in Cognitive Science, K. Akins, Ed., vol. 5, pp. 158-172, Oxford University Press, Oxford, UK, 1996.

[10] F. Stanco, L. Tenze, and G. Ramponi, "Virtual restoration of vintage photographic prints affected by foxing and water blotches," Journal of Electronic Imaging, vol. 14, no. 4, Article ID 043008, 2005.

[11] E. Sangregorio, F. Stanco, and D. Tanasi, “The archeomatica project: towards a new application of computer graphics in archaeology," in Proceedings of Eurographics Italian Chapter Conference, pp. 1-5, Dieter Fellner, Salerno, Italy, July 2008.

[12] F. Stanco, S. Battiato, and G. Gallo, Cultural Heritage Preservation. Analysis, Restoration and Reconstruction of Ancient Artworks, CRC Press, New York, NY, USA, 2011.

[13] D. Margounakis, "Virtual reconstructions in archaeology," in $E$ Learning Methodologies and Computer Applications in Archaeology, D. Politis, Ed., pp. 146-156, Information Science Reference, Hershey, Pa, USA, 2008.

[14] E. F. Anderson, L. McLoughlin, F. Liarokapis, C. Peters, P. Petridis, and S. de Freitas, "Serious games in cultural heritage," in State of Arts and Reports, Proceedings of the 10th International Symposium on Virtual Reality, Archaeology and Cultural Heritage (VAST), M. Ashley and F. Liarokapis, Eds., pp. 29-48, Eurographics Association, St Julians, Malta, September 2009.

[15] P. Reilly, "Three dimensional modeling and primary archaeological data," in Archaeology and the Information Age: A Global Perspective, P. Reilly and S. Rahtz, Eds., pp. 97-122, Routledge, London, UK, 1992.

[16] I. Hodder and L. Doughty, Eds., Mediterranean Prehistoric Heritage: Training, Education and Management, McDonald Institute of Archaeology, Cambridge, UK, 2007.

[17] C. Malone, S. Stoddart, A. Bonanno, and D. Trump, Mortuary Customs in Prehistoric Malta: Excavations at the BrochtorffCircle at Xaghra (1987-1994), McDonald Institute of Archaeology, Cambridge, UK, 2009.

[18] A. Chalmers and S. K. F. Stoddart, "Photorealistic graphics for visualising archaeological site reconstructions," in Imaging the Past. Electronic Imaging and Computer Graphics in Museums and Archaeology (British Museum Occasional Paper 114), A. Higgins, P. Main, and J. Lang, Eds., pp. 85-93, British Museum, London, UK, 1996.

[19] A. Chalmers and K. Debattista, "Investigating the structural validity of virtual reconstructions of prehistoric Maltese temples," in Proceedings of the 6th International Symposium on Virtual Reality, Archaeology and Cultural Heritage (VAST), M. Mudge, N. Ryan, and R. Scopigno, Eds., pp. 1-6, Eurographics Association, Aire-la-Ville, Switzerland, 2005.

[20] B. Flynn, "Exploration of Maltese prehistoric temples through the application of multimedia technologies," Mediterranean Archaeology and Archaeometry, vol. 5, no. 2, pp. 23-34, 2005.

[21] H. Bonnici, "The documentation of the built heritage using 3D laser scanning techniques," in Challenges in Conservation of Architectural Heritage, Civil EngIneering Encounters, R. P. Borg, Ed., pp. 91-97, Kamra tal-Periti, Malta, 2011.

[22] J. Mallia, "Bridging the gap: the megalithic temples in the 21st century," in Ta' Hagrat and Skorba: Ancient Monuments in a 
Modern World, M. E. Zammit and J. Mallia, Eds., pp. 119-130, Midsea Books, Sta Venera, Malta, 2008.

[23] D. F. Maune, Digital Elevation Model Technologies and Applications: The DEM Users Manual, American Society for Photogrammetry and Remote Sensing, Bethesda, Md, USA, 2007.

[24] M. Llobera, "Extending GIS-based visual analysis: the concept of visualscapes," International Journal of Geographical Information Science, vol. 17, no. 1, pp. 25-48, 2003.

[25] M. Dellepiane, M. Callieri, M. Corsini, and R. Scopigno, "Using digital 3D models for study and restoration of cultural heritage artifacts," in Digital Imaging for Cultural Heritage, S. Battiato, G. Gallo, and F. Stanco, Eds., pp. 39-70, CRC Press, New York, NY, USA, 2011.

[26] S. Moser, "Archaeological representation. The virtual conventions for constructing knowledge about the past," in Archaeological Theory Today, I. Hodder, Ed., pp. 262-283, Polity Press, Malden, Mass, USA, 2005.

[27] G. Pavlidis, A. Koutsoudis, F. Arnaoutoglou, V. Tsioukas, and C. Chamzas, "Methods for 3D digitization of cultural heritage," Journal of Cultural Heritage, vol. 8, no. 1, pp. 93-98, 2007. 

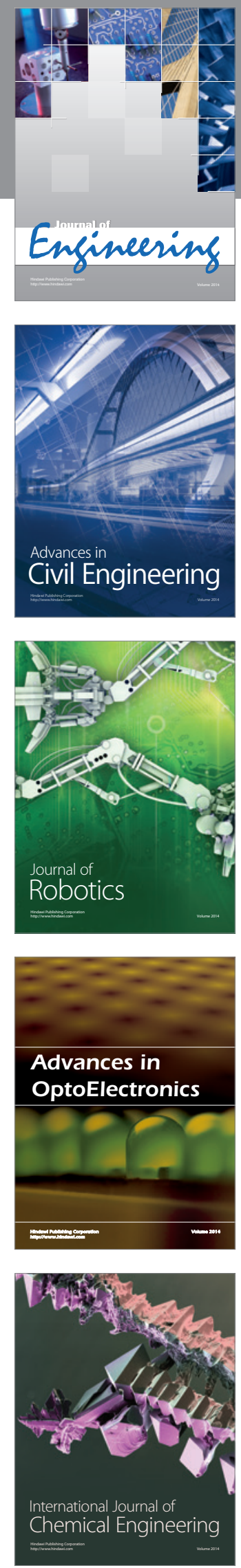

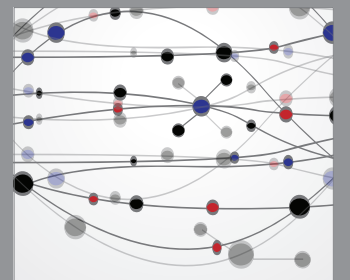

The Scientific World Journal
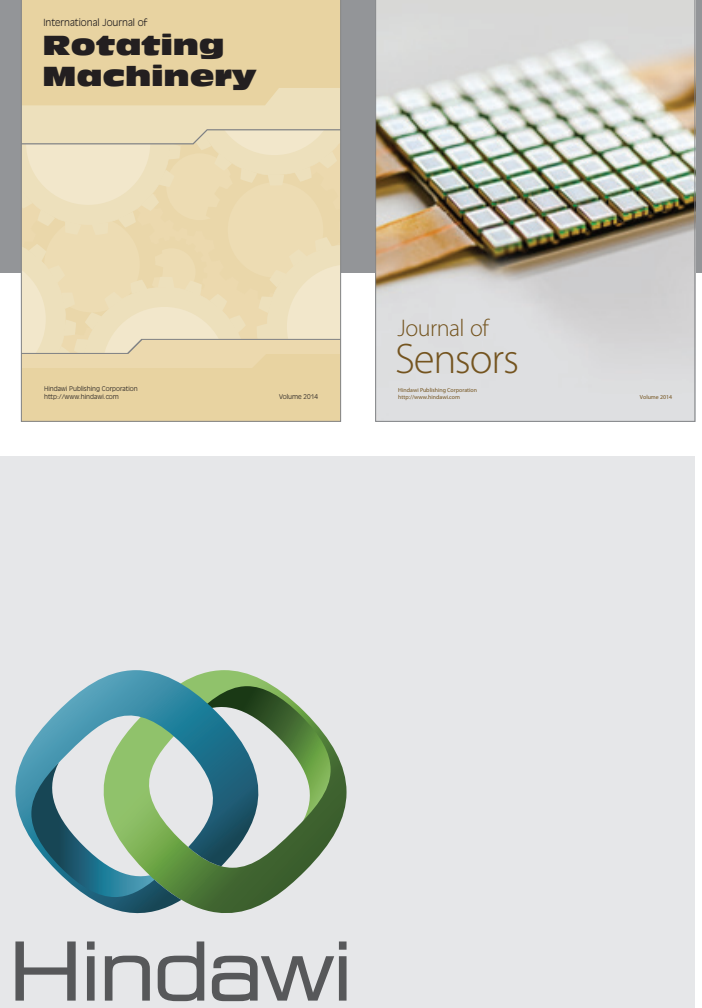

Submit your manuscripts at http://www.hindawi.com
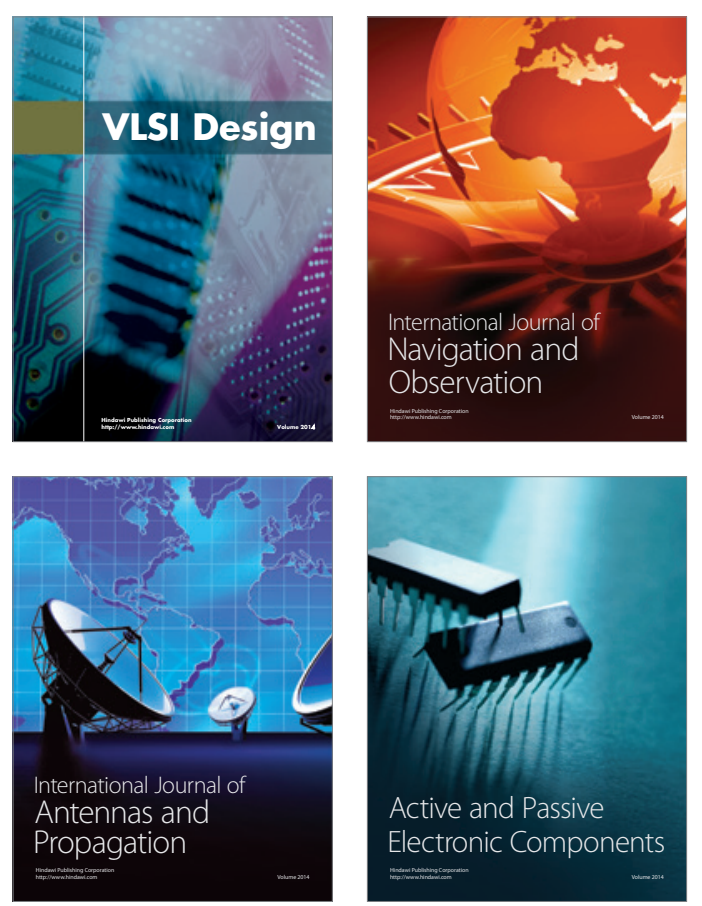
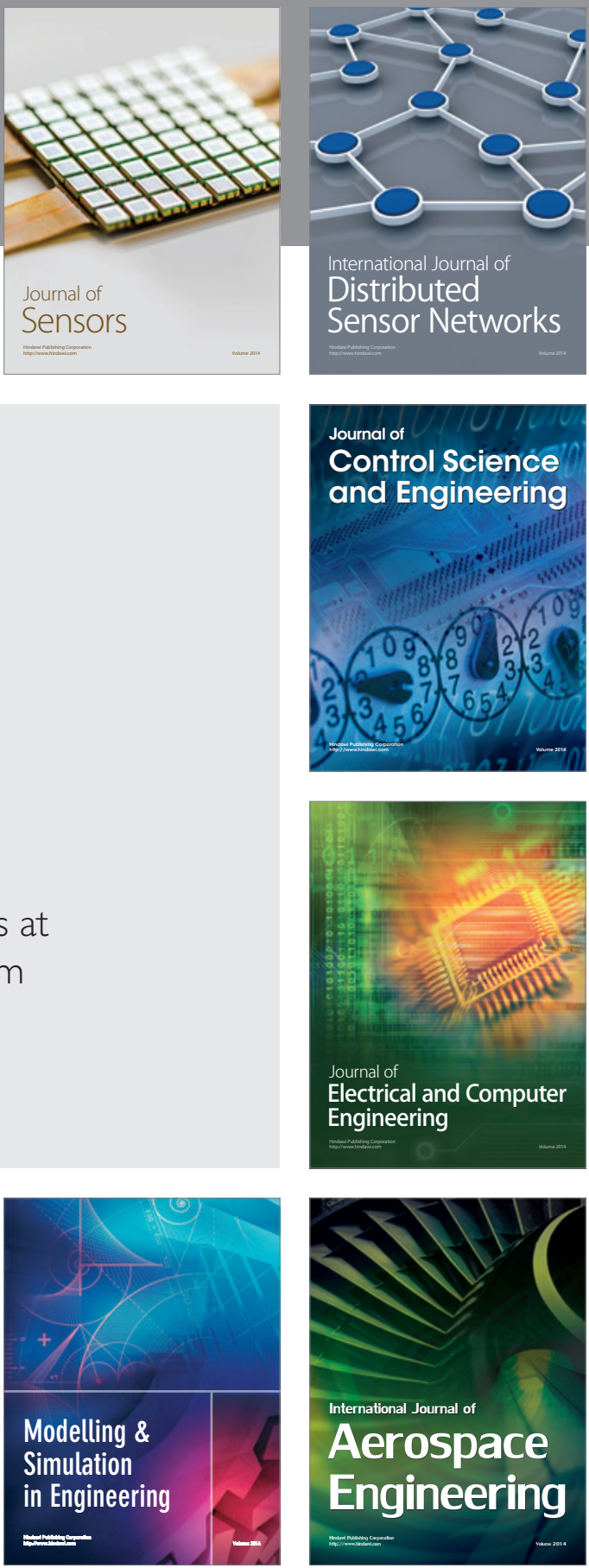

Journal of

Control Science

and Engineering
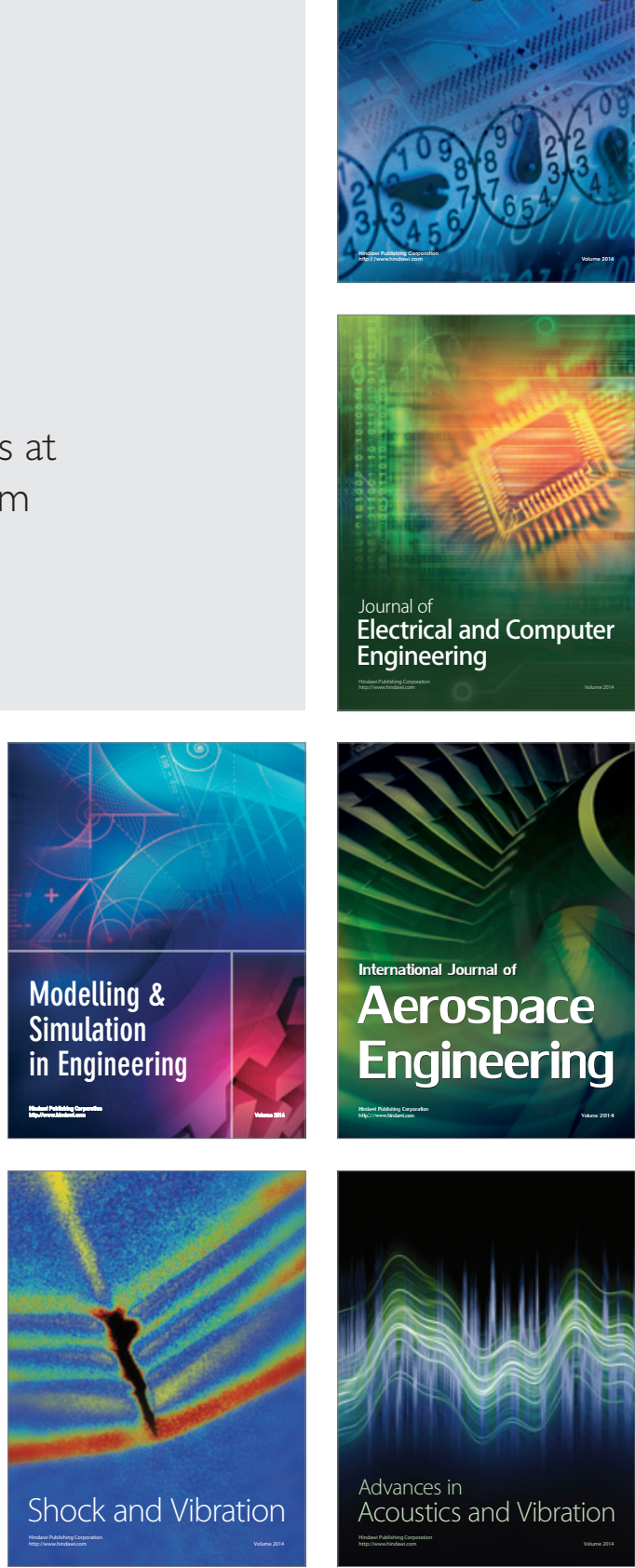